\title{
RAW MATERIALS ASPECTS OF NATIONAL SECURITY OF UKRAINE
}

\author{
Zhukov S.O., \\ Doctor of Sciences (Engineering), professor, \\ Kryvyi Rih National University, Ukraine \\ Palyvoda O.A., \\ Ph.D. (Engineering), associate professor, \\ Kryvyi Rih National University, Ukraine \\ Lutsenko S.O., \\ Ph.D. (Engineering), associate professor, \\ Kryvyi Rih National University, Ukraine
}

\begin{abstract}
Improving the national security of Ukraine is possible by expanding raw materials base of mining enterprises by substantiating prospective quarries contours. When determining the quarry boundaries, economic stripping ratio is calculated according to technical and economic indicators achieved at the time of design and its value is constant. However, the analysis of mining and processing plants operation showed that their economic indicators and stripping ratios change over time. It is proved that economic stripping ratio is not constant, but varies over time. The analytical method substantiates the condition of competitiveness of the designed quarry. On the example of quarries, which reflect the characteristic features of the development of steeply dipping deposits in Ukraine, the influence of technological indicators (current stripping ratio) of the existing quarries operation on the value of the economic stripping ratio and, accordingly, on the quarry final depth is graphically substantiated.

The methodology was developed for determining the boundaries of quarries, which provides for the application of the economic stripping ratio as a value that is not constant, but varies over time, and one that depends on changes in the current stripping ratio at competing quarries. The result of the study is that the theory in the field of determining quarries final contours has been improved. It is proved that the deviation of the final mining depth of the designed quarry, determined by comparing its current stripping ratio with the current stripping ratios of the conditional base competing quarries, from the final mining depth determined by the constant economic stripping ratio can reach $50 \%$.
\end{abstract}

Keywords: raw materials base, iron ore quarry, economic stripping ratio, quarry boundaries.

Introduction. One of the main parameters in the design of open pit mining is the boundaries of the quarry. The economic efficiency 
and duration of the enterprise operation, the full use of mineral reserves and investment volumes directly depend on the selected depth of open-pit mining.

As practice shows, the depth and position of the final contours of most major quarries, as they develop mineral deposits, are repeatedly reviewed and adjusted. However, it is mandatory to determine the final contours of quarrying, in which open pit mining will be effective.

Recent applied and scientific studies on this issue clearly indicate the need for reevaluation of the final contours of open pit mining in Ukraine. At the moment, the working boards of almost all quarries on the surface have approached or are approaching the project contours and are entering the reclamation process (in the process of transferring the working open pit side to the designed one). An example of such quarries can be powerful quarries of the Kryvyi Rih iron ore basin. The development of mining occurs only when it is lowered. Development within the boundaries approved by existing projects may lead to the rapid reclamation of the working open pit sides at the final design contours in the nearest future. If during this period we do not decide on the feasibility of expanding the design contours and allow the reclamation of the working sides, then in the future huge investments and a long time will be required to re-preserve the reclaimed sides. Therefore, it is now necessary to determine the possible prospects for the development of quarries and the feasibility of their reconstruction. In addition, this will entail a significant increase in the cost of open pit mining due to the re-conservation of non-working sides if the boundaries of the quarries are revised in the future.

In such conditions of mining, it is necessary to assess the capabilities of the raw materials base for the further development of the mining enterprise. Therefore, it is now necessary to determine the possible prospects for quarry development and the feasibility of revising and adjusting their boundaries. The further it is delayed in time, the greater will be the price and duration of the restoration of the design productivity of the raw ore quarries during the reconstruction of the quarries in case of further revision of the boundaries. In this regard, the interest of the owners of mining enterprises in the mining capabilities of the deposits transferred to them for exploitation increased: the final depth of the quarry, the remaining ore reserve in its contours, the 
maximum possible productivity of the quarry for ore, the volume of overburden operations, ensuring its achievement and others. These parameters determine the development prospect of the mining and processing plant and its industrial potential, the necessary investments and possible profits.

According to article 13 of the Constitution of Ukraine, natural resources are the subject of property rights of the Ukrainian people. Therefore, the state should control that the owners of the mining enterprises conduct the most complete development of the deposits that they have taken for use. From the above it follows that the problem of determining the prospective boundaries of quarries is relevant both for business entities that exploit mineral deposits and for the state and society overall.

Currently, quarries are being designed, in accordance with the decree of the Ministry of Industrial Policy of Ukraine; in accordance with the Technological design standards for mining enterprises with open pit method of mineral deposits development. This document does not actually reflect the latest scientific achievements in determining the boundaries of quarries, and does not fully take into account the current state of technology and technology of open pit mining.

Based on the above mentioned, increasing the national security of Ukraine is possible by expanding the raw materials base of mining enterprises through the development of a theoretical apparatus for quarry designing, as well as the development of specific applied methods and instructions for determining the boundaries of open pit mining, providing the most complete and cost-effective mining development of mineral deposits. Therefore, the purpose of the research described in the paper is to improve existing methods for determining the boundaries of quarries, focusing on the work of mining enterprises in a market economy.

Currently, in the theory and practice of designing, there is no single method for determining the boundaries of quarries developing steeply falling deposits. There are several well-known principles for substantiating the depth of quarries, based on a comparison of one of the stripping ratios or the sum of these ratios with the economic stripping ratio.

A major contribution to the development of the theory of designing the boundaries of open pit mining belongs to V.V. Rzhevsky [1], A.I. Arsentiev [2, 3], B.P. Yumatov [4], A.K. Polishchuk [5], V.S. Khokhria- 
kov [6] V.G. Blizniukov [7]. In these works, the determination of the economic stripping ratio was carried out based on comparing the performance indicators of the enterprise under study with the performance indicators of enterprises with an underground mining method, as well as with indicators of similar mining and processing plants. The price of marketable ore (products), which depends on its quality, has always determined the boundaries of open pit mining. However, when determining the boundaries of quarries according to the proposed calculation principles, the economic stripping ratio is calculated according to the technical and economic indicators achieved at the basic mining enterprises at the time of design, and its value is constant, while it does not take into account that the economic indicators and stripping ratios of the basic enterprises (competitive quarries) change over time.

Calculation principles. The economic basis of all the calculation principles for determining the boundaries of quarries is a comparison of the allowable cost price of ore mining $\left(c_{a}\right)$ with the expected of the designed career $\left(c_{\text {design. }}\right)$ [8], which is expressed by the inequality

$$
c_{a} \geq c_{\text {design. }}, \mathrm{UAH} / \mathrm{t} \text {. }
$$

To determine the boundaries of the quarry, ensuring the competitiveness of iron ore products, it is necessary to take into account the timevarying economic indicators of the base enterprises (competing quarries).

Therefore, the calculation principle is based on the fact that at any development period, the economic indicators of the production and sale of iron ore products of the designed enterprise should be less than or equal to the similar indicators of the existing (base) enterprise.

Thus, if quarries develop deposits with the same quality of minerals, then the cost price of ore is taken as the cost price of ore of one of the main competing mining competitive enterprises with an open pit method of developing deposits

$$
C_{\text {act. }} \geq C_{\text {design. }}
$$

In this case, the allowable cost price of ore is accepted as it is at the time of designing a new quarry or reconstruction of an existing one.

The expected cost price of ore for the designed quarry is calculated depending on the value of the stripping ratio $\left(n_{\text {design. }}\right)$ according to the formula, $\mathrm{UAH} / \mathrm{t}$

$$
c_{\text {design. }}=a+b \cdot n_{\text {design. }}, \mathrm{UAH} / \mathrm{t},
$$


where $a-$ cost price of ore mining without stripping soils expenses, UAH/t; $b$ - stripping expenses, $\mathrm{UAH} / \mathrm{m}^{3} ; n_{\text {design. }}$ - stripping ratio in the designed quarry, $\mathrm{m}^{3} / \mathrm{t}$.

After substituting the expected value of the cost price of ore mining and transforming inequality (2), formula (3) will take the following form, $\mathrm{m}^{3} / \mathrm{t}$

$$
\frac{C_{a c t .}-a}{b} \geq n_{\text {design. }}
$$

The left-hand side in expression (4) determines the value of the economic stripping ratio $\left(n_{\mathrm{e}}\right)$ and then, taking into account formulae (1, 3 and 4), we obtain the inequality, $\mathrm{m}^{3} / \mathrm{t}$

$$
n_{e} \geq n_{\text {design. }},
$$

Based on the foregoing, the condition for the competitiveness of the designed quarry can be formulated as follows: the stripping ratio for the designed quarry should not exceed the economic stripping ratio, which takes into account the economic indicators of the development of the existing (base) enterprise.

Determining the economic stripping ratio. Methods for determining the economic stripping ratio are classified according to the methods for determining the allowable cost price of ore.

Technological design standards [9] for mining enterprises with open pit method of mineral deposits development regulate determining the economic stripping ratio based on the comparison of the underground and open pit methods of development.

However, it should be understood that a comparison of the cost prices of the open pit and underground mining is not correct due to different volumes of production; the productivity of quarries significantly exceeds the productivity of mines, which covers the needs of the market to different extents. In addition, the cost price of production by underground mining remains equally high throughout the life of the mine, while the quarry reaches a peak in production cost price only in one of the operating periods, when the surface boundaries reach the final contour. Therefore, it is advisable to determine the economic stripping ratio at the wholesale price per unit of commodity products, its output from raw ore, and the expenses on enriching a unit of raw ore.

The use of the wholesale price as a criterion for determining the economic stripping ratio is not reliable when planning for long time 
periods. Thus, for example, when designing a quarry for 20-50 years, it is not possible to determine market demand and selling prices for minerals. In addition, the economic indicators of existing (base) enterprises, at the time of the new design preparation, are used in the calculations of the economic stripping ratio. In this case, the economic stripping ratio will be a constant value for the designed quarry. However, the analysis of the economic indicators of most operating mining and processing plants, even for a relatively short period of their work, showed their significant change, Table 1.

Table 1

Economic indicators of the production and sale of the concentrate at the mining and processing plants of Ukraine

\begin{tabular}{|c|c|c|c|c|c|}
\hline Enterprise & Years & $\begin{array}{l}\text { Cost price, } \\
\text { UAH/t }\end{array}$ & $\begin{array}{l}\text { Price, } \\
\text { UAH/t }\end{array}$ & $\begin{array}{l}\text { Expenses on } \\
\text { the } 1 \text { UAH of } \\
\text { commercial } \\
\text { products, } \\
\text { UAH/UAH }\end{array}$ & $\begin{array}{l}\text { The iron } \\
\text { content in } \\
\text { the concen- } \\
\text { trate, \% }\end{array}$ \\
\hline \multirow{5}{*}{$\begin{array}{l}\text { Northern Ore } \\
\text { Mining and Pro- } \\
\text { cessing Plant } \\
\text { (Northern GOK) }\end{array}$} & 2005 & 118,45 & 312,75 & 0,38 & \multirow{5}{*}{65,64} \\
\hline & 2010 & 272,67 & 907,25 & 0,30 & \\
\hline & 2013 & 343 & 858 & 0,40 & \\
\hline & 2015 & 430 & 1150 & 0,37 & \\
\hline & 2020 & 689,90 & 1850 & 0,37 & \\
\hline \multirow{5}{*}{$\begin{array}{l}\text { Central Ore Min- } \\
\text { ing and Pro- } \\
\text { cessing Plant } \\
\text { (Central GOK) }\end{array}$} & 2005 & 148,74 & 321,74 & 0,46 & \multirow{5}{*}{66,8} \\
\hline & 2010 & 350,72 & 957,74 & 0,37 & \\
\hline & 2013 & 397,18 & 900 & 0,44 & \\
\hline & 2015 & 540 & 1190 & 0,45 & \\
\hline & 2020 & 868,4 & 1920 & 0,44 & \\
\hline \multirow{5}{*}{$\begin{array}{l}\text { Southern Ore } \\
\text { Mining and Pro- } \\
\text { cessing Plant } \\
\text { (Southern GOK) }\end{array}$} & 2005 & 107,7 & 258,74 & 0,42 & \multirow{5}{*}{65,36} \\
\hline & 2010 & 337,3 & 1012 & 0,33 & \\
\hline & 2013 & 312,85 & 958 & 0,33 & \\
\hline & 2015 & 409,44 & 1233 & 0,33 & \\
\hline & 2020 & 622,08 & 1870 & 0,34 & \\
\hline \multirow{5}{*}{$\begin{array}{l}\text { Inguletsky Ore } \\
\text { Mining and Pro- } \\
\text { cessing Plant } \\
\text { (Inguletsky } \\
\text { GOK) }\end{array}$} & 2005 & 120,36 & 287,11 & 0,42 & \multirow{5}{*}{63,89} \\
\hline & 2010 & 327 & 921 & 0,36 & \\
\hline & 2013 & 364,71 & 1000 & 0,37 & \\
\hline & 2015 & 485 & 1210 & 0,40 & \\
\hline & 2020 & 721,6 & 1780 & 0,39 & \\
\hline
\end{tabular}

The table shows that from 2005 to 2020 , the cost price and price of marketable mineral products increased on average respectively by 600 and $700 \%$. 
From this, we can conclude that the economic stripping ratio for the designed quarry will change.

In the regulatory documents governing the operation of mining enterprises with an open pit mining method, the calculated economic stripping ratio for determining the final mining depth of the designed quarry is assumed constant. However, the competitive base enterprise continues its work, and over time its economic indicators will change, in our case, the cost price of ore will change. The reason for this is the change in the current stripping ratios up or down.

Let us consider the condition for changes in the current stripping ratios over time using two conventional base competing quarries, which are presented at characteristic sections of the developed deposits (Fig. 1 and Fig. 2).

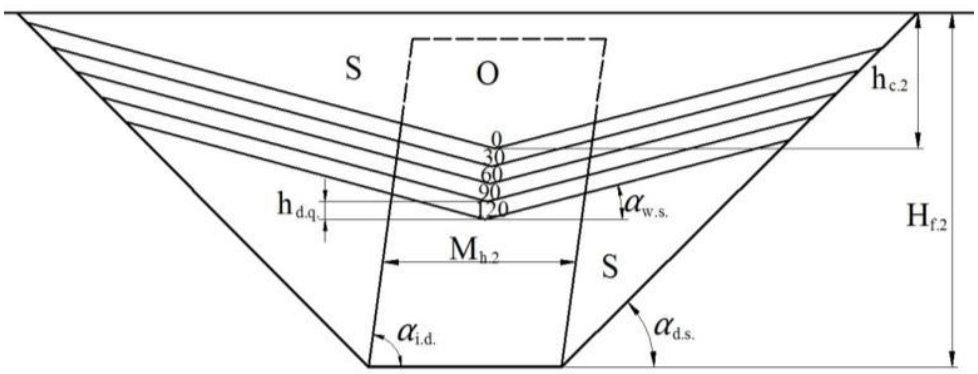

Fig. 1. Quarry №1: $\mathrm{S}$ - stripping soils; $\mathrm{O}$ - ore; $\mathrm{h}_{\mathrm{c} .1}$ - current depth of mining, $\mathrm{m}$; $\mathrm{h}_{\text {d.q. }}$ - step of dipping mining operations, $m ; \alpha_{\text {w.s. }}-$ slope angle of the working side of the quarry, degrees; $\alpha_{\text {d.s. }}-$ slope angle of the designed side of the quarry, degrees; $\alpha_{\text {i.d. }}-$ angle of inclination of ore deposit, degrees; $\mathrm{M}_{\mathrm{h} .1}$ - horizontal deposit thickness, $\mathrm{m}$; $\mathrm{H}_{\mathrm{f} .1}$ - final depth of the quarry, $\mathrm{m} ; 0,30,60,90,120$ - stages of lowering mining operations in the quarry

Conventional basic quarry №1 (Fig. 1) is developing an ore deposit in which: the angle of inclination is $80^{\circ}$; horizontal thickness -350 $\mathrm{m}$; length $-2700 \mathrm{~m}$. The parameters of this quarry are slope angle of the working side $-16^{\circ}$; slope of the designed side $-45^{\circ}$; final quarry depth $-630 \mathrm{~m}$. It should be noted that at the quarry №1, the surface boundaries have already approached the design position and further development of the open pit is carried out with the development of mining operations only in depth.

Conditional basic quarry №2 (Fig. 2) is developing an ore deposit in which: the angle of inclination is $80^{\circ}$; horizontal power $-120 \mathrm{~m}$; 
length $-4500 \mathrm{~m}$. The parameters of this quarry are slope angle of the working side $-16^{\circ}$; slope of the designed side $-45^{\circ}$; final quarry depth $-345 \mathrm{~m}$.

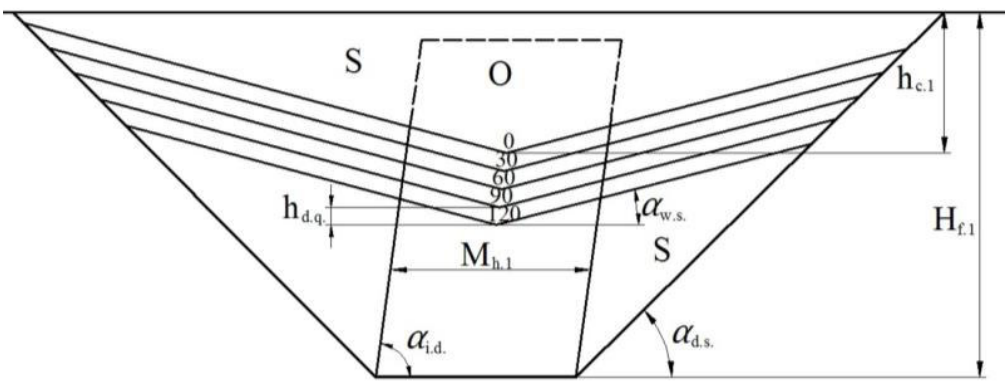

Fig. 2. Quarry №2: $\mathrm{S}$ - stripping soils; $\mathrm{O}$ - ore; $\mathrm{h}_{\mathrm{c} .2 .}$ - current depth of mining operations, $\mathrm{m}$; $\mathrm{h}_{\text {d.q. }}-$ step of dipping mining operations, $\mathrm{m}$; $\alpha_{\text {w.s. }}-$ slope angle of the working side of the quarry, degrees; $\alpha_{\text {d.s. }}-$ slope angle of the designed side of the quarry, degrees; $\alpha_{\text {i.d. }}$ - angle of inclination of ore deposit, degrees; $\mathrm{M}_{\mathrm{h} .2}$ - horizontal deposit thickness, $\mathrm{m} ; \mathrm{H}_{\mathrm{f} .2}$ - final depth of the quarry, $\mathrm{m} ; 0,30,60,90,120$ - stages of lowering the mining operations in the quarry

It should be noted that at conditional base quarry №2, the surface boundaries have not yet reached the designed position and further development of the quarry is carried out with the development of mining operations, both in the horizontal direction and in depth.

In the presented figures 1 and 2, the numbers 0, 30, 60, 90, 120 indicate the stages of calculating the volume of mining operations when they lower for every $30 \mathrm{~m}$. The position of the working side of the quarry at stage " 0 " characterizes the state of mining operations in the quarry and serves as a starting point for further studies of their development.

To simplify the study, the position of the working sides of quarries №1 and №2 at the zero stage was chosen so that the value of the current stripping ratios of these quarries was the same.

When designing a new quarry, firstly it is necessary to determine the prospective depth of open pit mining: it will determine the boundaries of the quarry in terms of surface and the possible productivity of the quarry in terms of a mineral deposit. A condition for determining the prospective boundaries of the designed quarry is to obtain economic indicators of the designed quarry no worse than the economic 
indicators of existing quarries. This condition is written by inequality (18).

To determine the final depth of the quarry of the future (conditional designed) quarry, a characteristic section is selected on the deposit intended for operation in which: the angle of inclination is $85^{\circ}$; horizontal thickness $-230 \mathrm{~m}$; length $-3200 \mathrm{~m}$. The other parameters are taken similar to quarries №1 and №2. All quarries exploit the deposits of the same type of mineral with the same quality, and the existing technology allows them to work with the conditionally equal expenses on extracting one ton of stripping soils and extracting one ton of ore.

Both at conditional base quarries №1 and №2, and for a conditional designed quarry, from the position of working sides at the zero stage, their further position is rebuild according to the stages of development of mining operations every $30 \mathrm{~m}$ in depth. At each stage, the volumes of ore and stripping soils are measured with the determination of the current stripping ratios, the calculation results are listed in Table 2.

For the designed quarry and the base operating quarries, we construct a graph (Fig. 3) for the change in the largest current stripping ratio, depending on the increase in the designed mining depth of the quarry $\left(\mathrm{H}_{\text {des.q. }}\right)$. The line of the calculated stripping ratio is also shown in the graph.

Table 2

Volumes of the ore and stripping soils, as well as current stripping ratios according to study options

\begin{tabular}{|c|c|c|c|c|c|c|}
\hline \multirow{2}{*}{ Quarries } & \multirow{2}{*}{ Volumes } & \multicolumn{5}{|c|}{ Quarry dipping, $\mathrm{m}$} \\
\hline & & 0 & 30 & 60 & 90 & 120 \\
\hline \multirow{3}{*}{$\begin{array}{l}\text { Condition- } \\
\text { al base } \\
\text { quarry №1 }\end{array}$} & Ore, $\mathrm{m}^{3}$ & 28080000 & 28080000 & 28080000 & 28080000 & 28080000 \\
\hline & $\begin{array}{l}\text { Stripping } \\
\text { soils, } \mathrm{m}^{3}\end{array}$ & $\begin{array}{l}10125000 \\
0\end{array}$ & 95445000 & 89775000 & 84240000 & 78435000 \\
\hline & $\begin{array}{l}\text { Stripping } \\
\text { ratio, } \mathrm{m}^{3} / \mathrm{m}^{3}\end{array}$ & 3,6 & 3,4 & 3,2 & 3,0 & 2,8 \\
\hline \multirow{3}{*}{$\begin{array}{l}\text { Condition- } \\
\text { al base } \\
\text { quarry №2 }\end{array}$} & Ore, $\mathrm{m}^{3}$ & 16425000 & 16425000 & 16425000 & 16425000 & 16425000 \\
\hline & $\begin{array}{l}\text { Stripping } \\
\text { soils, } \mathrm{m}^{3}\end{array}$ & 59400000 & 80325000 & 88650000 & 92025000 & 90000000 \\
\hline & $\begin{array}{l}\text { Stripping } \\
\text { ratio, } \mathrm{m}^{3} / \mathrm{m}^{3}\end{array}$ & 3,6 & 4,9 & 5,4 & 5,6 & 5,5 \\
\hline \multirow{3}{*}{$\begin{array}{l}\text { Condition- } \\
\text { al designed } \\
\text { quarry }\end{array}$} & Ore, $\mathrm{m}^{3}$ & 21920000 & 21920000 & 21920000 & 21920000 & 21920000 \\
\hline & $\begin{array}{l}\text { Stripping } \\
\text { soils, } \mathrm{m}^{3}\end{array}$ & 47680000 & 68800000 & 87520000 & 109760000 & 126880000 \\
\hline & $\begin{array}{l}\text { Stripping } \\
\text { ratio, } \mathrm{m}^{3} / \mathrm{m}^{3}\end{array}$ & 2,2 & 3,1 & 4,0 & 5,0 & 5,8 \\
\hline
\end{tabular}




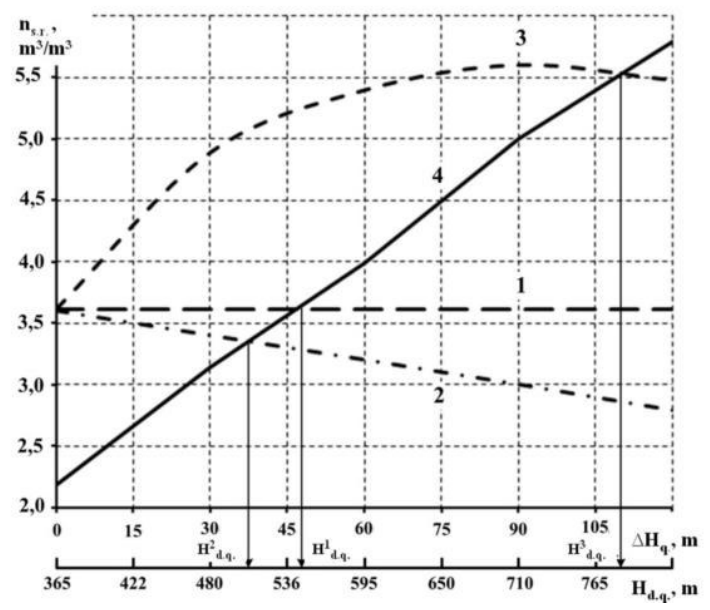

Fig. 3. A graph of the dependence of stripping ratios on lowering mining operations at the stages of dipping quarries with determining the final mining depth of a conditional designed quarry: 1 - economic stripping ratio; 2 - current stripping ratio in conditional base quarry №1; 3 - current stripping ratio in conditional base career №2; 4 - current stripping ratio according to the conditional designed quarry

In these cases, the current stripping ratios of the conditional base quarries №1 and №2 will also be economic stripping ratios for the conditional designed quarry.

If we calculate the economic stripping ratio for a newly designed quarry without taking into account the time-varying current stripping ratios of the base quarries №1 and №2, as accepted before the present studies, it will be constant, line 1 in Fig. 3.

The intersection of these lines (lines 1, 2, 3 in Fig. 3) with the line of the current stripping ratio at the conditionally designed quarry (line 4 in Fig. 3) will give a solution to the final depth of the designed quarry with various methods for determining the economic stripping ratio.

Thus, for the designed quarry, three values of the final mining depth were obtained:

- $\mathrm{H}^{1}{ }_{\text {des.q. }}$ - final mining depth of the quarry, determined by the economic stripping ratio without taking into account its changes in time, is $560 \mathrm{~m}$; 
$-\mathrm{H}_{\text {des.q. }}^{2}$ - final mining depth of the quarry, determined by the time-varying current stripping ratio of the quarry №1 and being the economic stripping ratio for the designed quarry, is $485 \mathrm{~m}$;

$-\mathrm{H}_{\text {des.q. }}^{3}$ - final mining depth of the quarry, determined by the time-varying current stripping ratio of the conventional base quarry №2 and being the economic stripping ratio for the designed quarry, is $800 \mathrm{~m}$

The graphical solution for determining the final depth of the conditional designed quarry is presented in Fig. 4.

Fig. 3 shows that the deviation of the final mining depth of the conditional designed quarry, determined by comparing its current stripping ratios with the current stripping ratios of the conditional base quarries, from the final mining depth determined by the economic stripping ratio (by the outdated method) is from 14 to $45 \%$.

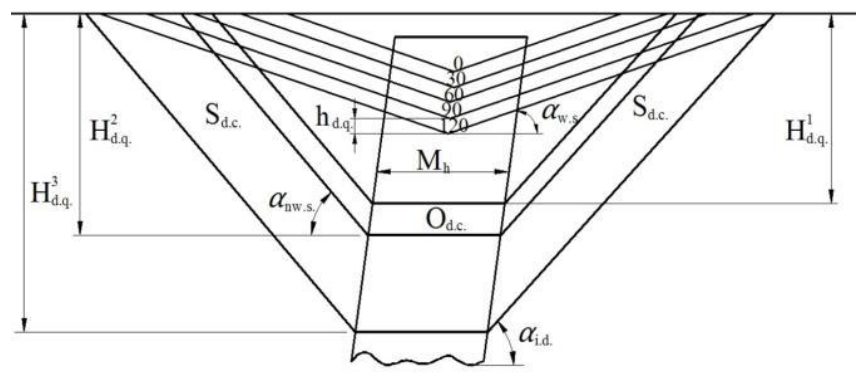

Fig. 4 Cross-section of the deposit, which will be developed by the conditional designed quarry: $\mathrm{S}_{\text {d.c. }}$ - stripping soils in the designed contours of the quarry; $\mathrm{O}_{\text {d.c. }}-$ ore in the designed contours of the quarry; $h_{\text {d.q. }}$ - step of dipping mining operations, $\mathrm{m}$; $\alpha_{w . s .}$ - angle of the working side of the quarry; $\alpha_{\text {nw.s. }}$ - angle of the non-working side of the quarry; $\alpha_{\text {i.d. }}$ - angle of inclination of ore deposit; $\mathrm{M}_{\mathrm{h}}$ - horizontal deposit thickness; $0,30,60,90,120$ - stages of lowering mining operations in the quarry; $\mathrm{H}_{\text {d.q. }}^{1}$ final mining depth of the quarry, determined by the economic stripping ratio; $\mathrm{H}_{\text {d.q. }}^{2}$ final mining depth of the quarry, determined by the current stripping ratios of the conditional base quarry № $1 ; \mathrm{H}^{3}$ d.q. - final mining depth of the quarry, determined by the current stripping ratios of the conventional base quarry № 2

Mainly two indicators - the cost price of marketable mineral products and its price, determine the competitiveness of a mining enterprise, like any other. The cost price of marketable mineral products, even of a similar type, depends on the natural conditions of the deposit, the existing structure of the enterprise, the achieved level of organization and production technology, and other factors that depend on 
the qualifications of the management. Therefore, the difference in the quality and cost price of marketable mineral products (concentrate as its first type) at various mining and processing plants is quite understandable and explainable. However, the price of marketable mineral products on the sales markets should depend only on the quality of the products.

Previously, when there was a planned economy and economic indicators were stable, the price of marketable mineral products was determined solely on the content of the useful component in it. Currently, the price of marketable mineral products depends not only on objective factors (environmental conditions, production technology, etc.); subjective factors also influence it a lot: the skills and competence of the management team, agreements between the buyer and seller of products, the use of methods to minimize tax obligations, and others.

If the price of the concentrate depends only on its objective factors (qualitative characteristics), then the price of $1 \%$ iron in the concentrate would be relatively the same at all plants. Therefore, a methodology was proposed [10] for determining the economic stripping ratio, which avoids the influence of unnatural and non-technological factors on the price of the concentrate. The bottom line is that the price of the concentrate of the designed mining and processing plant is provided at the price of the percentage of iron per tonne of concentrate of the base mining and processing plant (competitive enterprise), $\mathrm{UAH} / \mathrm{t}$

$$
P_{\text {design. }}^{\prime}=\frac{P_{\text {bas. }} \cdot F e_{\text {design. }}}{F e_{\text {bas. }}},
$$

where $P_{\text {design. }}^{\prime}$ - provided price of the concentrate of the designed mining and processing plant;

$F e_{\text {bas. }}$ and $F e_{\text {design. }}$ - the content of iron in the concentrate of the base designed mining and processing plant, $\%$.

Table 1 shows that the expenses of $1 \mathrm{UAH}$ of marketable mineral products have a slight change - by $2-3 \%$. Therefore, if quarry contours are designed under the condition that the economic indicators of concentrate production at the designed mining and processing plant should be no worse than the similar indicators of the compared plants, 
then it is necessary for the calculations to take (as the base enterprise) the indicators of the mining and processing plants with the smallest expenses per $1 \mathrm{UAH}$ of produced and sold concentrate

$$
E_{\text {bas. }} \geq E_{\text {design. }}
$$

where $E_{\text {bas. }}$ and $E_{\text {design. }}$ - expenses per $1 \mathrm{UAH}$ of produced and sold concentrate at the base and designed mining and processing plants, $\mathrm{UAH} / \mathrm{UAH}$.

Then,

$$
\frac{C_{\text {bas. }}}{P_{\text {bas. }}} \geq \frac{C_{\text {design. }}}{P_{\text {design. }}}
$$

where $C_{\text {bas. }}$ and $C_{\text {design. }}$ - the cost price of the concentrate production at the base and designed mining and processing plants, UAH/t; $P_{\text {bas. }}$ and $P_{\text {design. }}$ - the price of the sale concentrate at the base and designed mining and processing plants relatively, UAH/t.

From here, the economic stripping ratio for the quarry of the designed mining and processing plant, determined through comparing the economic efficiency of production and sale of concentrate at the basic mining and processing plant, will be equal to, $\mathrm{m}^{3} / \mathrm{t}$

$$
n_{e}=\frac{E_{\text {bas. }} \cdot P_{\text {design. }}^{\prime} \cdot \gamma_{q}-\left(a_{D a}+a_{D p}\right)}{B_{D}},
$$

where $E_{\text {bas. }}$ - expenses per $1 \mathrm{UAH}$ of the marketable mineral products of the base enterprise, UAH.

Based on the results of the performed studies, we can confidently state the following. In order to determine the boundaries of the designed quarry, the economic stripping ratio must be determined taking into account the possible changes in the extraction volumes of stripping soils and ore at the base competitive enterprises which perform mining operations both in an open pit and underground method, i.e. taking into account changes in their current stripping ratios.

It should be noted that ignoring changes in the economic stripping ratio over time can lead to both an excess and an underestimation of the economically feasible depth of the designed and existing quarries. The error in the accuracy of determining the boundaries of quarries that do not take into account market conditions reaches $50 \%$.

The conducted studies made it possible to justify the new calculation principle for determining the boundaries of quarries. It can be 
formulated as follows: the final depth of the quarry should be such that during its operation the sum of the initial and maximum current stripping ratio does not exceed the time varying appropriate economic stripping ratio, which depends on the technical and economic indicators of the base enterprises operation. At the same time, the current stripping ratio reaches its maximum value at the time of mining operations on the level of the daily surface at the final design contours.

The algorithm for determining the quarry boundaries according to this calculation principle is as follows:

1. On a characteristic transverse geological section or overall plan for mining operations, several options for quarry contours along the surface are outlined and the corresponding values for the final quarry depth are determined in accordance with the accepted slope angles of the non-working sides.

2. For each planned option, the position of mining operations is rebuilt at the moment of their exit by the level of the day surface to the design contours of the quarry and the values of the largest current stripping ratios are determined.

3. Based on the calculation results, is built up a graph (Fig. 5) of changes in the largest current stripping ratios depending on changes in the depth of mining operations for the same time period $n_{\text {тmax }}=f\left(h_{\text {г.р. }}\right)$. To determine the final depth of the quarry under the abscissa axis, we construct an additional scale for changing the final depth of the quarry $n_{\mathrm{rmax}}=f\left(H_{\mathrm{K}}\right)$. While determining the boundaries of quarries developing elongated deposits, when the design is carried out at several transverse sections for different areas of the deposit, we construct graphs of changes in the largest current stripping ratios depending on changes in the depth of mining operations for each area $n_{\text {Tmax }}=\mathrm{f}\left(\mathrm{h}_{\text {г.p. }}\right)$ and from an increase in the final depth of the quarry $n_{\mathrm{rmax}}=f\left(H_{\mathrm{\kappa})}\right.$ in the same areas.

4. The values of the economic stripping ratio are calculated taking into account the time varying technical and economic indicators of the base enterprise, as well as the reduction of prices to one type of marketable mineral product at the price of one percent of iron per ton of concentrate. 


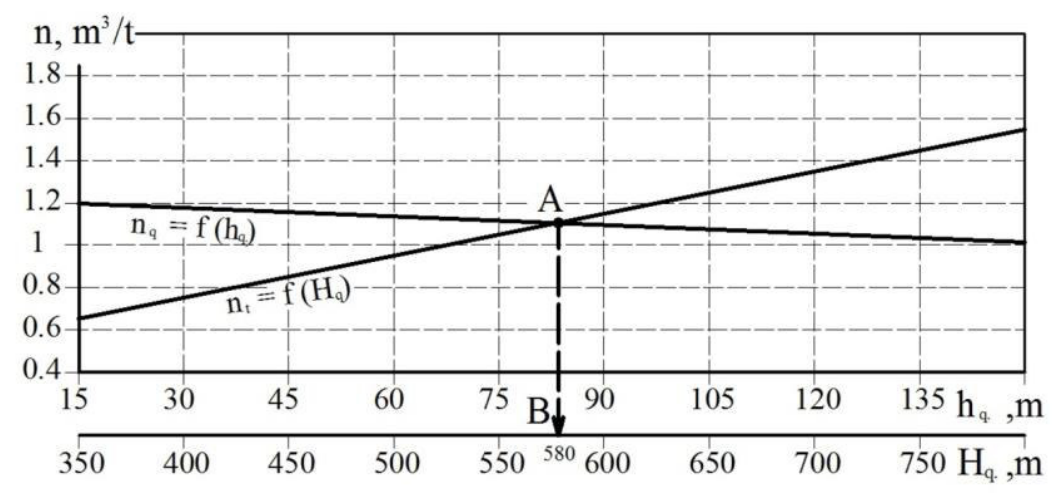

Fig. 5. Graphs of changes in the largest current tripping ratios depending on the increase in the depth of mining operations of the designed quarry from the current state

5. The intersection point of the curve reflecting the change in the largest current stripping ratio of the designed quarry with the lines of the economic stripping boundary (point A in Fig. 5) is determined and the prospective quarry depth is determined in comparison with the base enterprise (point B in Fig. 5).

Conclusions. A new calculation principle has been developed for determining the boundaries of quarries, which provides for the application of the economic stripping ratio as a value that is not constant, but varies over time, and one that depends on changes in the current stripping ratios at competing quarries.

The economic basis for the calculation principle for determining the prospective depth of a designed quarry is the following condition: at any period of development, the economic indicators of the production and sale of iron ore products of the designed enterprise should be better than or equal to those of the existing (base enterprise for comparison) enterprise. 
The error in the accuracy of determining the boundaries of quarries that do not take into account market conditions reaches $50 \%$. This calculation principle allows you to expand the raw materials base of mining enterprises and thereby increase the national security of Ukraine.

\section{References}

1. Rzhevskiy, V.V. (1961), Designing quarry contours, Moscow: Metallurgizdat.

2. Arsentiev, A.I. (1961). Determining the final depth of quarries. Proceedings of Kryvyi Rih Ore Mining Institute, Vol. 10, 97-115.

3. Arsentiev, A.I. (1970), Determining quarry productivity and boundaries, Moscow: Nedra.

4. Yumatov, B.P. (1962), The effect of grade and minimum industrial content on the depth and productivity of quarries. News of higher educational institutions. Mining Journal, Vol.2, 45-53.

5. Arsentiev, A. I., Polishchuk, A.K. (1967), Development of methods for determining quarry boundaries, Leningrad: Nauka.

6. Khokhriakov, V.S. (1980), Quarry designing, Moscow: Nedra.

7. Blizniukov, V.G. (1978), Determination of the main indicators of the quarry taking into account the ore quality, Moscow: Nedra.

8. Anistratov, Yu.I. (2002), Quarry designing, Moscow: Research and production company "Gemos Limited".

9. Ministry of Industrial Policy of Ukraine (1963), Technological design standards for mining enterprises of iron and steel industry with open pit method of development, Leningrad: Giprorud.

10. Blisniukov, V.G., Baranov, I.V., Savitsky, A.V. (2012), Exclusion of subjective factors in determining the final contours of iron ore quarries as part of mining and processing plants. Bulletin of Kryvyi Rih National University, Vol. 94, Kryvyi Rih: SHEI KNU, 3-6. 